\title{
Wavelet Packet Decomposition-Based Fault Diagnosis Scheme for SRM Drives With a Single Current Sensor
}

\author{
Chun Gan, Student Member, IEEE, Jianhua Wu, Shiyou Yang, Yihua Hu, Senior Member, IEEE, \\ and Wenping Cao, Senior Member, IEEE
}

\begin{abstract}
Power converters are a key, but vulnerable component in switched reluctance motor (SRM) drives. In this paper, a new fault diagnosis scheme for SRM converters is proposed based on the wavelet packet decomposition (WPD) with a dc-link current sensor. Open- and short-circuit faults of the power switches in an asymmetrical half-bridge converter are analyzed in details. In order to obtain the fault signature from the phase currents, two pulse-width modulation signals with phase shift are injected into the lower-switches of the converter to extract the excitation current, and the WPD algorithm is then applied to the detected currents for fault diagnosis. Moreover, a discrete degree of the wavelet packet node energy is chosen as the fault coefficient. The converter faults can be diagnosed and located directly by determining the changes in the discrete degree from the detected currents. The proposed scheme requires only one current sensor in the dc link, while conventional methods need one sensor for each phase or additional detection circuits. The experimental results on a 750-W three-phase SRM are presented to confirm the effectiveness of the proposed fault diagnosis scheme.
\end{abstract}

Index Terms-Current sensor, discrete degree, fault diagnosis, node energy, power converter, pulse-width modulation (PWM), switched reluctance motor (SRM), wavelet packet decomposition (WPD).

\section{INTRODUCTION}

I N RECENT years, switched reluctance motors (SRMs) have attracted much attention from industry and research community, primarily due to their rare-earth-free feature, while competing permanent magnet machines rely on rare-earth materials (e.g., neodymium and dysprosium). The SRM has a simple and rugged rotor structure, as well as advantages of high efficiency, low cost, and high reliability [1]-[4]. It is particularly suited for high-speed and safety-critical applications [5], [6]. The SRM is

Manuscript received April 13, 2015; revised July 20, 2015; accepted August 28,2015 . This work was supported in part by the Chinese National 863 Program under Grant 2011AA11A101 and the National Nature Science Foundation of China under Grant 51377139. Paper no. TEC-00253-2015.

C. Gan, J. Wu, and S. Yang are with the College of Electrical Engineering, Zhejiang University, Hangzhou 310027, China (e-mail: ganchun.cumt@ 163.com; hzjhwu@163.com; shiyouyang@yahoo.com).

$\mathrm{Y}$. Hu is with the Department of Electronic and Electrical Engineering, University of Strathclyde, Glasgow G1 1XQ, U.K. (e-mail: Yihua.hu@strath.ac.uk).

W. Cao is with the School of Electronics, Electrical Engineering, and Computer Science, Queen's University Belfast, Belfast BT7 1NN, U.K., and also with the Department of Electrical Engineering and Computer Science, Massachusetts Institute of Technology, Cambridge, MA 02139 USA (e-mail: w.cao@qub.ac.uk).

Color versions of one or more of the figures in this paper are available online at http://ieeexplore.ieee.org.

Digital Object Identifier 10.1109/TEC.2015.2476835 also considered as a competitive solution for electric propulsion in electric vehicles and hybrid electric vehicles [4], [7]-[10].

It is known that SRM drives are fault-tolerant by their nature [11]-[13], but not completely fault-free. For instance, power converters are a key component in motor drives and their power switches are the most susceptible to failures, especially in harsh environments. In practice, open- and short-circuit faults of the power switches are the common failures [14]-[16], which lead to an adverse impact on the system performance. Although the SRM can still operate if a phase leg is lost to failure, its electromagnetic and mechanical performance deteriorates to some degree and the rotor is subjected to unbalanced force.

Some state-of-the-art technologies are proposed in [17][21], to identify the open- and short-circuit faults for brushless dc (BLDC) motor, permanent-magnet synchronous motor (PMSM), and induction motor (IM) drives. In [17], the wavelet transform is used to extract the diagnostic indices from the dclink current waveform under open-switch conditions for BLDC motor drives. An online fault diagnosis method for BLDC inverter with a dc-dc buck converter is proposed in [18]. Based on the residual signals of the voltage observers, the method can detect both open- and short-circuit faults in power switches. In [19], a model reference adaptive system is developed to detect open-circuit faults in power switches of PMSM inverters. Another diagnostic method for open-circuit faults in the closedloop controlled PMSM drives is presented in [20], based on the current residual vector. In [21], a simple diagnostic method for single-switch and double-switch open-circuit faults is developed for pulse-width modulation (PWM) voltage-source inverters in vector controlled IM drives.

For SRMs, electrical faults are classified in details in [22], and several remedial strategies are also presented. The artificial neural networks (ANNs) and evolutionary algorithms-based model [23], and the ANNs and genetic algorithms-based model [24] are employed to predict the performance of SRM drives under normal and faulty operating conditions. In [25], two schemes by monitoring the chopped bus current and by detecting the upper freewheeling bus current and excitation bus current are proposed and compared in detail for power switch faults. The work in [26] presents a fault diagnostic technique for open- and short-circuit faults in SRM power switches, based on the difference between the measured and estimated dc-link currents. However, one extra current sensor is also needed in addition to the phase current sensors, increasing the cost and volume of the drive. In [27], a similar diagnostic method is proposed based on the difference 


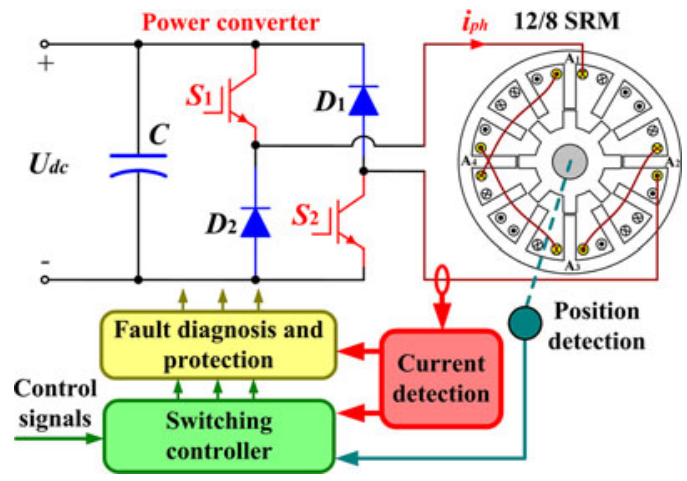

Fig. 1. 12/8-pole SRM drive system for one phase leg.

between the averages of the phase currents. Moreover, the supply current polar chart is used for converter faults analysis [28]. Other techniques such as current differential detectors and flux differential detectors [29] are found in SRM drives for faults detection. A fault diagnosis scheme by using voltage dividers and comparators to monitor the voltage of lower-switches is presented in [30], for an inverter-fed SRM drive. However, they need additional detection circuits and inevitably increase the cost and complexity to the motor drive. Fast Fourier transform (FFT) algorithm is employed in [31] and [32] to analyze the supply current of the power converter subjected to open- and short-circuit faults. Nevertheless, the effective fault coefficient is not presented, and the diagnosis accuracy is easily affected by the spectrum energy leakage from the FFT algorithm. As a result, there is a need to develop an effective, reliable and low-cost diagnostic method for SRM converter faults.

In general, effective fault diagnosis requires accurate current tracking in a motor drive. Conventionally, a current sensor is installed in each phase to track the phase current. In order to reduce the cost and volume of the motor drive, some technologies [33]-[37] use a single current sensor to detect the phase current from the dc-link current. A tristate PWM technique is employed in [33] to reconstruct the phase current of the IM drive using dc current information. In [34], a new phase current reconstruction method is proposed for PMSM servo inverters using a single dc-link current sensor by applying phase-shifts to the switching-state waveforms. This leads to lower output current ripples and switching losses. A new algorithm using a single dc-link current sensor to reconstruct all three phase currents of the inverters is proposed in [35], by applying additional active voltage vectors for brief intervals during each fundamental frequency cycle. A pulse injection method of phase current reconstruction from dc-link current is presented in [36] for SRM converters. A six-phase current reconstruction scheme with a single dc-link current sensor for dual traction inverters is proposed in [37], by using advanced phase shift for all PWM signals based on the sequence of duty cycles.

This paper proposes a new fault diagnosis scheme for SRM drives based on the wavelet packet decomposition (WPD) algorithm and a single dc-link current sensor. It employs the discrete WPD because of its good frequency resolution and localization.

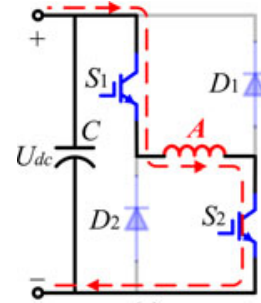

(a)

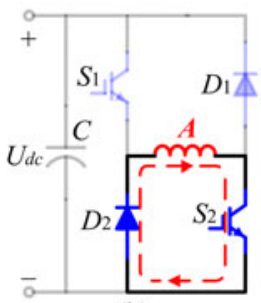

(b)

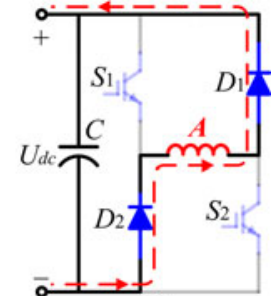

(c)
Fig. 2. Operation modes of the converter. (a) Excitation mode. (b) Freewheeling mode (ZVL). (c) Demagnetization mode.

Open- and short-circuit faults in power switches in an asymmetrical half-bridge converter are analyzed in details. Two phaseshifted PWM signals with the same frequency and duty-cycle are injected simultaneously into the lower-switch of each phase for excitation current detection. Furthermore, a discrete degree of the wavelet packet node energy is used as the fault coefficient to diagnose and locate the faults. The proposed scheme requires only one current sensor in the dc-link without any hardware investment. The experiments carried out on a three-phase 12/8-pole SRM are presented to confirm the effectiveness and implementation of the proposed fault diagnosis scheme.

\section{ANALYSIS OF FAULTS IN POWER SWITCHES}

\section{A. SRM Drive}

Fig. 1 shows a 12/8-pole SRM drive system for one phase leg. The current detection is very important to diagnose the fault that occurs in the drive to implement protections. A conventional asymmetrical half-bridge converter is usually employed in the SRM drive, due to its phase isolation, excellent stability and fault tolerance performance. The power switches in the drive are a vulnerable part, most prone to failures.

In order to reduce the switching power loss, a soft-chopping mode is used such that the upper-switch chops and the lowerswitch remains closed in the phase turn-on region [25]. There are mainly three operation modes for the converter, as shown in Fig. 2. When switches $S_{1}$ and $S_{2}$ are both $O N$ in the phase turnon region, the current flows in phase A winding immediately, and the phase leg works in the excitation mode, as shown in Fig. 2(a). When $\mathrm{S}_{1}$ is OFF and $\mathrm{S}_{2}$ is ON, the phase A current is in a zero-voltage loop (ZVL), and the phase leg works in the freewheeling mode, as shown in Fig. 2(b). When $S_{1}$ and $S_{2}$ both shut OFF in the phase turn-off region, the phase current flows back to the power source through diodes $\mathrm{D}_{1}$ and $\mathrm{D}_{2}$, and the phase leg works in the demagnetization mode, as shown in Fig. 2(c).

A speed-controlled closed-loop SRM drive with voltagePWM regulation scheme is shown in Fig. 3. The speed error is processed by a speed controller, such as a proportional integral (PI) controller. The motor speed is obtained from a speed calculator using an encoder to detect the rotor position. The turn-on and turn-off angles ( $\theta_{\text {on }}$ and $\left.\theta_{\text {off }}\right)$ are determined by the position detector to control the phase commutation. The phase voltage is the control issue, which is addressed by the 


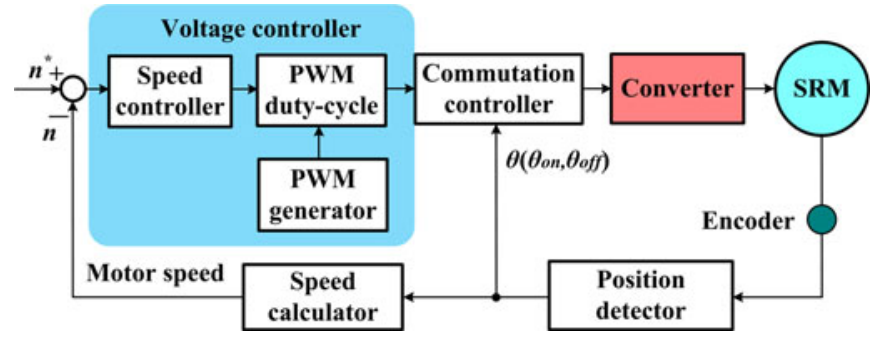

Fig. 3. Control diagram for SRM drives.

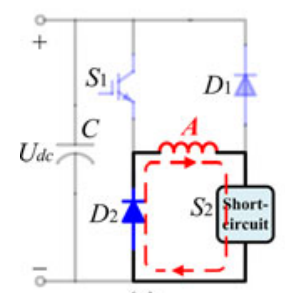

(a)

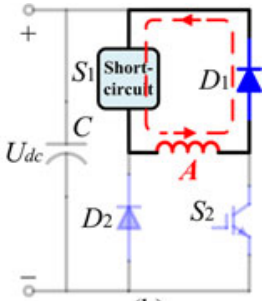

(b)
Fig. 4. Short-circuit fault condition. (a) $S_{2}$ short-circuit. (b) $S_{1}$ short-circuit.

voltage controller. The PWM duty-cycle is regulated by a PWM generator according to the instantaneous speed.

\section{B. Open-Circuit Fault}

If there is an open-circuit fault developed in the upperswitches or lower-switches, the system will work in the phase absence state. The average electromagnetic torque under healthy conditions is given by

$$
T_{\mathrm{av}}=\frac{m N_{r}}{2 \pi} \int_{0}^{2 \pi / N_{r}} T_{e}(\theta, i) d \theta
$$

where $m$ is the phase number, $N_{r}$ is the number of rotor poles, $\theta$ is the rotor angular position, $i$ is the phase current, and $T_{e}(\theta, i)$ is the phase instantaneous torque depending on the rotor position and phase current.

When one phase leg is open-circuited, the faulty phase loses excitation and other phases can still operate normally, due to the phase isolation of the converter. The average electromagnetic torque becomes

$$
T_{f \mathrm{av}}=\frac{m-1}{m} T_{\mathrm{av}} .
$$

In a closed-loop system, the currents in the healthy phases will increase to produce the required torque output, due to the adjustment of the speed controller. However, the unbalanced phase currents increase the torque ripple and reduce the load capacity.

\section{Short-Circuit Fault}

When the lower-switch $S_{2}$ is short-circuited, the only freewheeling mode is illustrated in Fig. 4(a); when the short-circuit fault of upper-switch $S_{1}$ occurs, the only freewheeling mode is illustrated in Fig. 4(b). In both faulty conditions, the phase current in the phase turn-off region is in a ZVL.

In healthy conditions, the voltage equation (e.g., phase A) in the phase turn-on region is given by

$$
U_{a}=D U_{\mathrm{dc}}=R_{a} i_{a}+L_{a}\left(\theta_{r}, i_{a}\right) \frac{d i_{a}}{d t}+i_{a} \omega_{r} \frac{d L_{a}\left(\theta_{r}, i_{a}\right)}{d \theta_{r}}
$$

where $D$ is the PWM duty-cycle, $U_{\mathrm{dc}}$ is the dc-link voltage, $R_{a}$ is the phase A winding resistance, $i_{a}$ is the phase A current, $\theta_{r}$ is the rotor position, $L_{a}\left(\theta_{r}, i_{a}\right)$ is the phase $\mathrm{A}$ winding inductance depending on the rotor position and phase current, and $\omega_{r}$ is the rotor angular speed.

When $\mathrm{S}_{2}$ is short-circuited, the phase A voltage still can be modulated normally by the PWM signal in $\mathrm{S}_{1}$, and phase A leg can still be controlled freely in the phase turn-on region. In the phase turn-off region, $\mathrm{S}_{1}$ is turned OFF and phase A current is in a ZVL through $D_{2}$, as shown in Fig. 4(a). The phase A current cannot flow back to the power source, and the demagnetization current cannot decrease to zero, which enters into the inductance descending region. A negative torque is generated according to

$$
T_{a}=\frac{1}{2} i_{a}^{2} \frac{d L_{a}\left(\theta_{r}, i_{a}\right)}{d \theta_{r}} .
$$

In this state, the torque ripple is increased due to the negative torque.

When $S_{1}$ is short-circuited, in the phase turn-on region, the PWM-voltage control scheme cannot be implemented by $S_{1}$, the voltage on phase A winding is the dc-link voltage, and the phase currents are more unbalanced compared to $\mathrm{S}_{2}$ short-circuited state. The voltage equation can be expressed as

$$
U_{a}=U_{\mathrm{dc}}=R_{a} i_{a}+L_{a}\left(\theta_{r}, i_{a}\right) \frac{d i_{a}}{d t}+i_{a} \omega_{r} \frac{d L_{a}\left(\theta_{r}, i_{a}\right)}{d \theta_{r}} .
$$

Similarly, in the phase turn-off region, $\mathrm{S}_{2}$ is turned OFF and phase A current is in a ZVL through $D_{1}$, as shown in Fig. 4(b). The phase current cannot flow back to the power source, which makes the current enter into the inductance descending region and increases the torque ripple.

\section{Proposed Fault Diagnosis Scheme}

\section{A. Phase Current}

Fig. 5 shows the relationship between the phase currents and switching states. In the figure, $i_{a}, i_{b}$, and $i_{c}$ are the phase A, B, and C currents, respectively; $S_{2}, S_{4}$, and $S_{6}$ are the drive signals for the lower-switches of phases A, B, and C, respectively; $\theta_{1}$, $\theta_{4}$, and $\theta_{5}$ are the turn-on angle, turn-off angle, and current ending angle for phase $\mathrm{B}$, respectively; $\theta_{2}$ is the turn-off angle of phase $\mathrm{A}$; and $\theta_{3}$ is the turn-on angle of phase $\mathrm{C}$.

There are four regions in the diagram. Regions I and III are the excitation current overlapping regions. Hence, the dc-link current in this region is the sum of the overlapped excitation currents. In Region II, there are the excitation current of phase $\mathrm{B}$ and demagnetization current of phase $\mathrm{A}$ in the dc-link current. In Region IV, the dc-link current contains both the demagnetization current of phase $\mathrm{B}$ and the excitation current of phase $\mathrm{C}$. If the demagnetization currents are all removed from the dc-link 


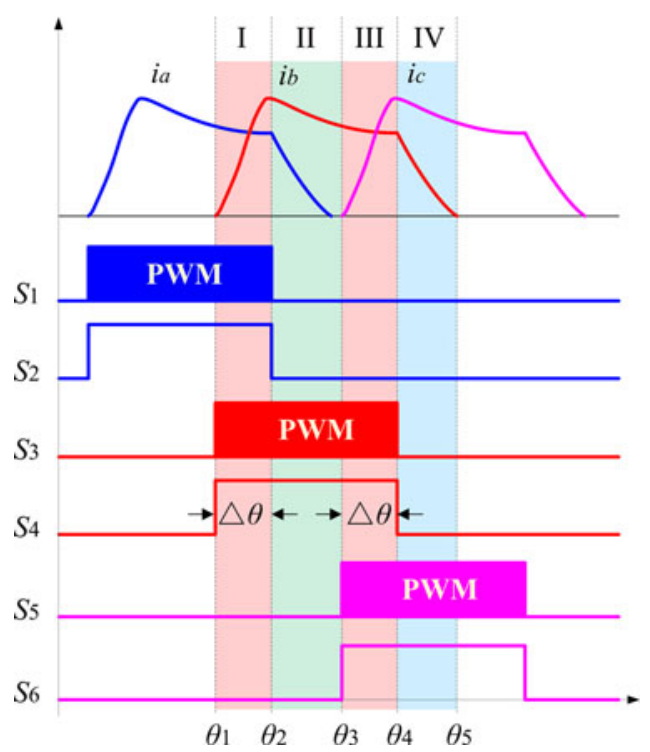

Fig. 5. Relationship between the phase currents and switching states.

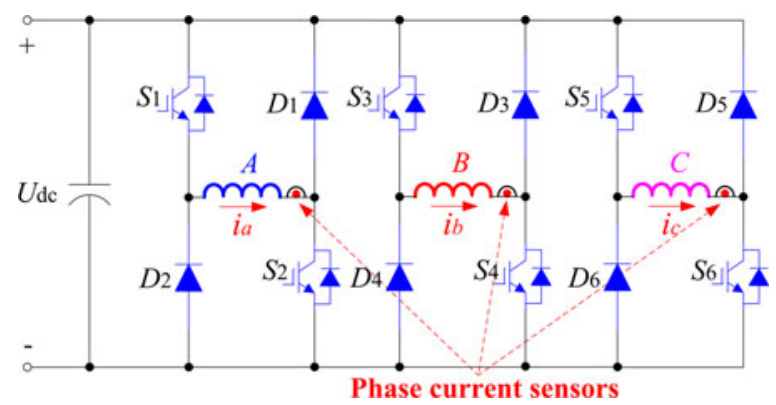

Fig. 6. Conventional current sensor placement strategy.

current, only the excitation current of phase B is present in the dc-link current in Region II, and only the excitation current of phase $\mathrm{C}$ is contained in the dc-link current in Region IV. Hence, the dc-link current without the demagnetization current contained in the rotor position region of $\theta_{1}-\theta_{5}$ can be expressed as

$$
i_{\mathrm{dc}}= \begin{cases}i_{a}+i_{b}, & \theta_{1}<\theta \leq \theta_{2} \\ i_{b}, & \theta_{2}<\theta \leq \theta_{3} \\ i_{b}+i_{c}, & \theta_{3}<\theta \leq \theta_{4} \\ i_{c}, & \theta_{4}<\theta \leq \theta_{5} .\end{cases}
$$

\section{B. Excitation Current Detection Using a Single DC-Link Current Sensor}

Conventionally, a current sensor is used individually in each phase winding to measure every phase current, as shown in Fig. 6. However, the used current sensors inevitably add the cost and volume to the motor drive. In order to obtain a compact and cost-effective system, a single dc-link current sensor strategy is proposed in Fig. 7. The positive terminals of all lowerdiodes are connected together to the cathode of the power source, and all the emitters of the lower-switches are also connected

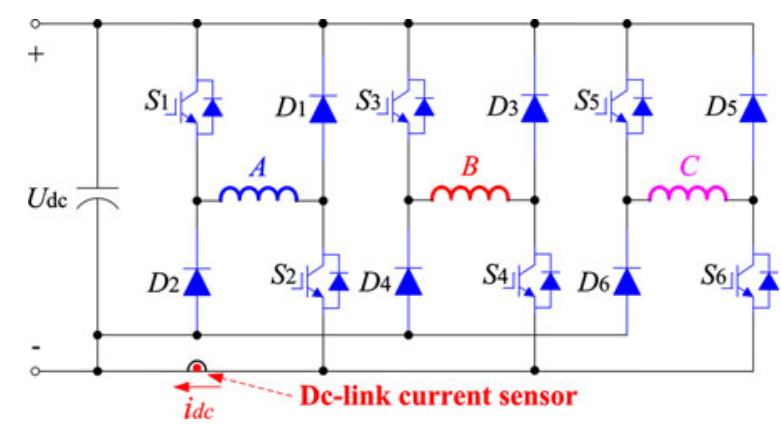

Fig. 7. Proposed dc-link current sensor placement strategy.

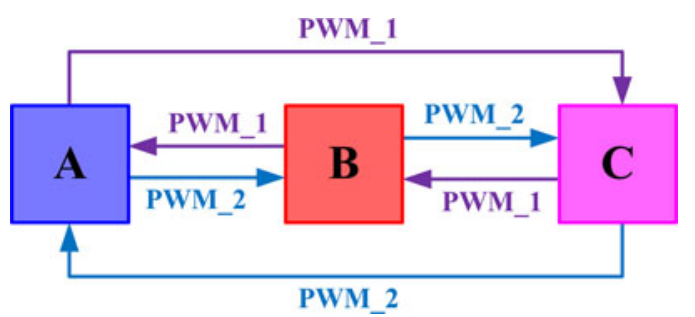

Fig. 8. PWM injection mode.

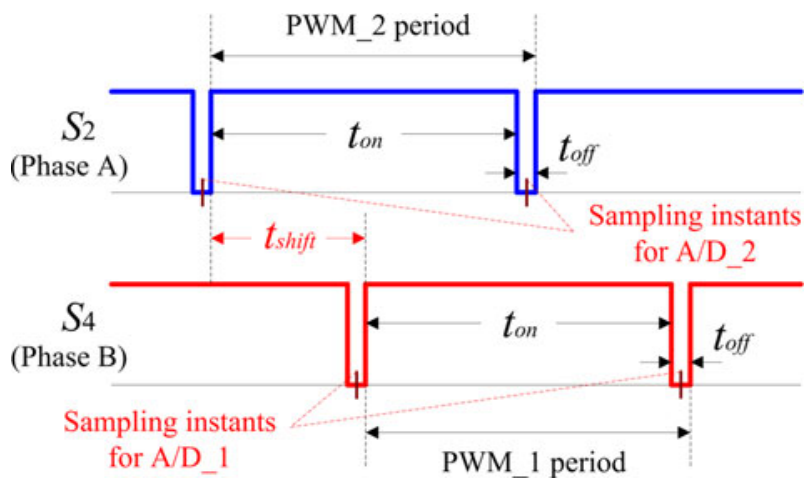

Fig. 9. Sampling instants and phase-shift condition.

together though a dc-link current sensor to the cathode of the power source. The proposed topology only has the excitation and freewheeling modes across the dc-link current sensor, without the demagnetization current of each phase contained in the proposed dc-link current.

The switching functions of the converter are defined as

$$
\mathrm{S}_{2,4,6}= \begin{cases}1, & \text { Lower }- \text { switch is ON } \\ 0, & \text { Lower }- \text { switch is OFF. }\end{cases}
$$

According to the phase currents and switching functions, the dc-link current can be expressed as

$$
i_{\mathrm{dc}}=i_{a} S_{2}+i_{b} S_{4}+i_{c} S_{6} .
$$

In order to obtain the excitation currents from the dc-link current, a phase-shifted PWM injection method is proposed and the PWM injection mode is shown in Fig. 8. Fig. 9 shows the sampling instants and phase-shift condition, where $t_{\text {on }}$ and $t_{\text {off }}$ are the turn-on and turn-off times of the PWM in a fundamental frequency cycle, and $t_{\text {shift }}$ is the phase-shift time between the two 
PWM signals. For example, PWM_1 is injected into the lowerswitch of phase $B$ in the excitation current overlapped region of phases A and B (Region I). The lower-switch of phase B is shut OFF in the turn-off time of PWM_1. According to the new converter configuration in Fig. 7, phase B current does not flow in the current sensor, and there is only the excitation current of phase $\mathrm{A}$ in the dc-link current during the inserted turn-off time of PWM_1. In this condition, one analog to digital (A/D) converter channel A/D_1 is triggered in the PWM_1 pause middle to detect the excitation current of phase A from the dc-link current. Furthermore, in order to detect the excitation current of phase B in Region I, the lower-switch of phase A should be shut OFF in other staggered turn-off times. Therefore, PWM_2, shifted by $t_{\text {shift }}$ from PWM_1, is injected into the lower-switch of phase A in the overlapped region of phases A and B. Similarly, phase A current does not flow in the current sensor, and there is only the excitation current of phase B in the dc-link current during the inserted turn-off time of PWM_2. In this condition, another A/D converter channel A/D_2 is triggered in the PWM_2 pause middle to detect the excitation current of phase B from the dclink current. Based on this technique, the excitation currents can be separated and detected individually in their overlapped regions. Therefore, the excitation current of each phase in the phase turn-on region can be completely obtained by follows:

$$
\begin{aligned}
i_{a \_r e}= & i_{\mathrm{dc} \_ \text {PWM } 2} \cdot S_{2} \cdot S_{6}+i_{\mathrm{dc} \_\mathrm{PWM} 1} \cdot S_{2} \cdot S_{4} \\
& +i_{\mathrm{dc}} \cdot S_{2} \cdot \overline{S_{2} S_{6}} \cdot \overline{S_{2} S_{4}} \\
i_{b_{\_} r e}= & i_{\mathrm{dc} \_\mathrm{PWM} 2} \cdot S_{2} \cdot S_{4}+i_{\mathrm{dc} \_\mathrm{PWM} 1} \cdot S_{4} \cdot S_{6} \\
& +i_{\mathrm{dc}} \cdot S_{4} \cdot \overline{S_{2} S_{4}} \cdot \overline{S_{4} S_{6}} \\
i_{c \_r e}= & i_{\mathrm{dc} \_\mathrm{PWM} 2} \cdot S_{4} \cdot S_{6}+i_{\mathrm{dc} \_\mathrm{PWM} 1} \cdot S_{2} \cdot S_{6} \\
& +i_{\mathrm{dc}} \cdot S_{6} \cdot \overline{S_{4} S_{6}} \cdot \overline{S_{2} S_{6}}
\end{aligned}
$$

where $S_{2}, S_{4}$, and $S_{6}$ are the drive signals prior to the PWMs injection; $i_{a \_r e}, i_{b_{\text {} \_r e}}$, and $i_{c \_r e}$ are the detected excitation currents for phases $\mathrm{A}, \mathrm{B}$, and $\mathrm{C}$, respectively; $i_{\mathrm{dc} \_\mathrm{PWM} 1}$ and $i_{\mathrm{dc} \_\mathrm{PWM} 2}$ are the measured dc-link currents with PWM_1 and PWM_2 injections in the pause middle of the PWMs in Regions I and III, respectively; and $i_{\mathrm{dc}}$ is the sampled dc-link current without any PWM injection in Region II.

As illustrated in Fig. 9, in order to ensure an effective sampling when injecting the PWM signals, the phase-shift time $t_{\text {shift }}$ should be limited to avoid the simultaneous turn-off of two phases. Therefore

$$
t_{\text {off }}<t_{\text {shift }}<t_{\text {on }} .
$$

The frequency and duty-cycle of the injected PWM should be set both large enough to ensure a high sampling precision for the excitation current detection and small impact on the actual phase current. However, considering the sensing tolerance of the current sensors, the maximum duty-cycle should be limited to allow a sufficient measurement time [38].

\section{Discrete Degree of the Wavelet Packet Node Energy}

In this paper, the excitation current detection scheme with the WPD algorithm is used for fault diagnosis. Based on this,

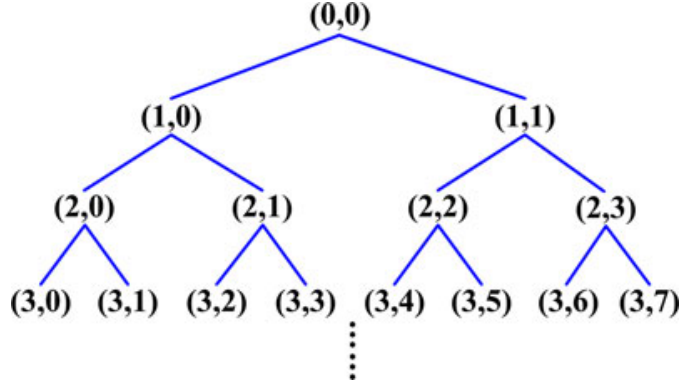

Fig. 10. Illustrative diagram of the WPD.

an effective fault coefficient is proposed. Owing to good frequency resolution and localization [39], the WPD algorithm is applied to the detected excitation current within a current period to extract the fault coefficient. WPD is an extension of the wavelet transform by combining multiresolution approximation with wavelets. The algorithm is to decompose one node into two nodes step by step, i.e., subdividing the whole frequency band of the sampled signal into small segments, as shown in Fig. 10. Obviously, if the decomposition level is $l$, the number of the nodes after decomposition is 2 .

The wavelet packet algorithm includes the decomposition and reconstruction for the wavelet packet coefficients. The decomposition algorithm for the coefficients is obtained by

$$
\left\{\begin{array}{l}
d_{k}^{j+1,2 n}=\sum_{k} h_{0(2 l-k)} d_{l}^{j, n} \\
d_{k}^{j+1,2 n+1}=\sum_{k} h_{1(2 l-k)} d_{l}^{j, n}
\end{array}\right.
$$

where $d_{l}^{j, n}, d_{k}^{j+1,2 n}$, and $d_{k}^{j+1,2 n+1}$ are all the wavelet packet coefficients, and $\left.h_{0(2 l-k}\right)$ and $\left.h_{1(2 l-k}\right)$ are the low-pass and high-pass filter coefficients for decomposition, respectively.

The reconstruction algorithm for the wavelet packet coefficients is deduced as

$$
d_{l}^{j, n}=\sum_{k} g_{0(l-2 k)} d_{k}^{j+1,2 n}+\sum_{k} g_{1(l-2 k)} d_{k}^{j+1,2 n+1}
$$

where $g_{0(l-2 k)}$ and $g_{1(l-2 k)}$ are the low-pass and high-pass filter coefficients for reconstruction, respectively.

For instance, if the decomposition level is five, the number of the obtained nodes is 32 after the wavelet packet algorithm calculations. Hence, the frequency band of the sampling signal is subdivided into 32 small segments. The wavelet packet coefficient of each node on the fifth level can be calculated from (13) and (14). The energy of node $j$ on the fifth level is given by

$$
E(5, j)=\int|S(5, j)(t)| d t=\sum_{k=1}^{n}\left|d_{j, k}\right|^{2}
$$

where $d_{j, k}(j=0,1, \ldots, 31 ; k=1,2, \ldots, n)$ is the wavelet packet coefficient for the reconstructed signal $S(5, j)$.

Hence, the discrete degree of the node energy can be expressed as

$$
\sigma=\left\{\frac{1}{k} \sum_{n=1}^{k}\left[E(5, n)-E_{\mathrm{av}}\right]^{2}\right\}^{\frac{1}{2}}
$$


This article has been accepted for inclusion in a future issue of this journal. Content is final as presented, with the exception of pagination.

TABLE I

Proposed Fault Diagnosis Technique Comparing With Existing Fault Diagnosis Methods

\begin{tabular}{|c|c|c|c|c|c|c|}
\hline & Proposed method & Paper [23], [24] & Paper [25] & Paper [26] & Paper [27] & Paper [29] \\
\hline Current sensor & One & One for each phase & Two & One for each phase +1 & One for each phase & One for each phase \\
\hline Fault diagnosis & Easy & Complicated & Complicated & Easy & Complicated & Easy \\
\hline Fault tolerance & Yes & Yes & Yes & Yes & Yes & Yes \\
\hline Robustness & High & Low & Low & High & Low & High \\
\hline Circuitry change & Minor & No & Medium & No & No & No \\
\hline Cost & Low & High & Medium & High & High & High \\
\hline
\end{tabular}

where $E_{\text {av }}$ is denoted as

$$
E_{\text {av }}=\frac{1}{k} \sum_{n=1}^{k} E(5, n)
$$

where $E(5, n)$ is the energy of node $n$ on the fifth level, $k$ is the selected number of the nodes, and $E_{\text {av }}$ is the average of the nodes energy.

The discrete degree of the wavelet packet node energy is calculated from the detected excitation current within a current period, and it is defined as the fault coefficient for fault diagnosis and location of the faulty switch.

\section{Comparison of the Proposed Fault Diagnosis Scheme with Existing Strategies}

A detailed comparison of the proposed fault diagnosis technique with existing fault diagnosis methods is presented in Table I. The ANN algorithm is employed in [23] and [24] for prediction of motor performance under faulty conditions, which is relatively difficult and complex, and the variations of the control parameters are not considered in this ANN-based model. An offline table of the current states under different faults is presented in [25] by detecting the upper freewheeling bus current and excitation bus current, and the converter circuit is modified for the current sensors installation. However, it is not suited for online angle modulation and variable load systems. In [26], one extra current sensor is needed in addition to the phase current sensors to measure the dc-link current for comparison with the estimated dc-link current calculated from the phase currents, which increase the cost and complexity of the drive. In [27], the difference between the averages of the phase currents is calculated to diagnose the faults for SRM drives with four current sensors used for four phases. The diagnostic system under different control parameters is not investigated. Additional detection devices including current differential detector and flux differential detector are utilized in [29] for faults detection, which increase the cost and complexity to the motor drive.

Compared to the existing schemes in [23]-[27], and [29], the proposed fault diagnosis scheme uses only a dc-link current sensor without any additional diagnosis devices and much change to the circuitry, which will considerably reduce the volume and complexity of the motor drive. The proposed scheme is found to be more accurate and easier to implement for fault diagnosis purposes by extracting the fault coefficient from the detected current through WPD algorithm. The cost is determined by the number of current sensors and additional detection circuits

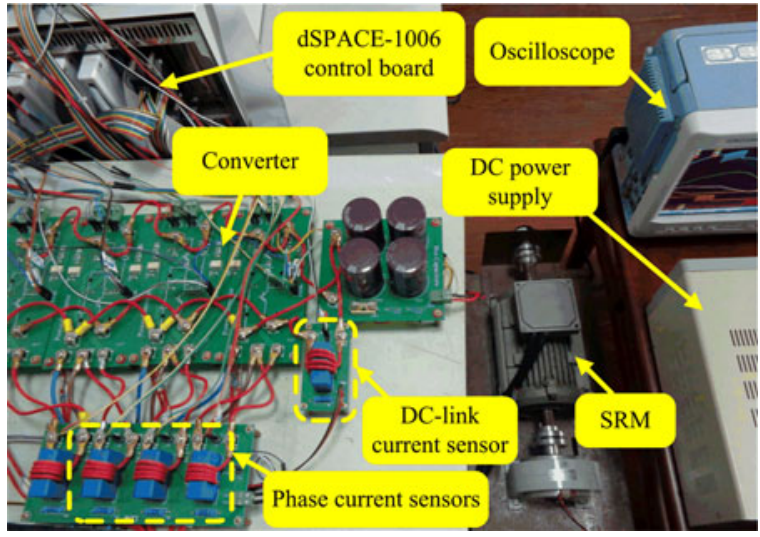

Fig. 11. Experimental setup.

employed in the diagnosis system. The proposed fault diagnosis scheme offers a low-cost solution to typical power switch faults. It has excellent robustness to the variations of system parameters, including the speed regulation, angle modulation, and load variation, which will be proved in the next section.

\section{EXPERIMENTAL VERIFICATION}

The proposed fault diagnosis method is experimentally validated on a $750-\mathrm{W}$ three-phase 12/8-pole prototype SRM. The experimental setup is shown in Fig. 11. A dSPACE-DS1006 control board is used as the main controller to implement the proposed scheme. An adjustable dc power supply is employed in the system to drive an asymmetrical half-bridge converter with a $60-\mathrm{V}$ voltage. The dc-link current is detected by a Halleffect current sensor (LA-55P), and simultaneously sampled by a 14-bit A/D converter. For comparison, three additional current sensors are installed in each phase leg to measure the phase currents. The power switches are IGBTs IKW75N60T and the diodes are IDW75E60.

Fig. 12 shows the block diagram of the implemented SRM drive control strategy. Two PWM signals with phase shift are injected into the lower-switches to generate the new drive signals for the converter, and the phase currents are detected from the sampled dc-link current through the operational amplifiers. The injected PWM signals are running with $10-\mathrm{kHz}$ switching frequency, $95 \%$ duty-cycle, and $50-\mu$ s phase-shift time. The rotor position and motor speed are obtained from an incremental encoder. A PI algorithm is employed in the system to regulate the motor speed via the closed-loop control. 


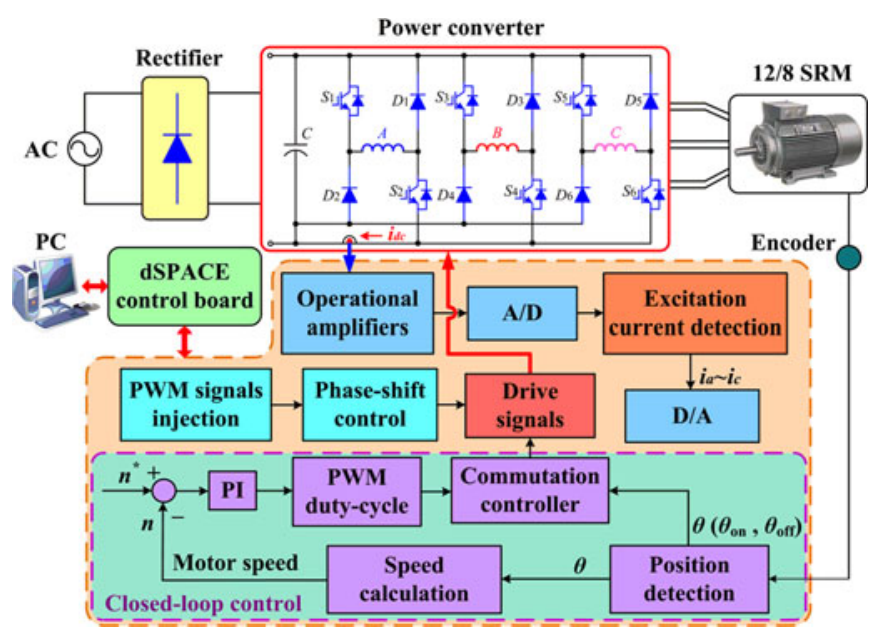

Fig. 12. Block diagram of the implemented SRM drive control strategy.

\section{A. Excitation Current Detection}

Fig. 13 shows the phase current detection in healthy conditions at $600 \mathrm{r} / \mathrm{min}$ and $1-\mathrm{N} \cdot \mathrm{m}$ load. Clearly, in Fig. 13(a), the dc-link current is the sum of the excitation currents. In order to detect the phase B current, PWM_2 is injected into the lowerswitch of phase $\mathrm{A}$ in the overlapped region of phases $\mathrm{A}$ and $\mathrm{B}$, and $A / D \_2$ is triggered in the PWM $\_2$ pause middle to sample the excitation current of phase B in this region; and PWM_1 is injected into the lower-switch of phase $\mathrm{C}$ in the overlapped region of phases $\mathrm{B}$ and $\mathrm{C}$, and $\mathrm{A} / \mathrm{D} \_1$ is triggered in the PWM_1 pause middle to sample the excitation current of phase $\mathrm{B}$ in this region, as shown in Fig. 13(b). PWM_2 and PWM_1 are injected simultaneously into the lower-switches of phases $B$ and $C$ in their overlapped regions, and A/D_2 and A/D_1 are triggered in PWM_2 and PWM_1 pause middle, respectively, to separate the overlapped excitation currents, as shown in Fig. 13(c). Clearly, due to a large duty-cycle and a high frequency, the turnoff time of the injected PWM is extremely short, which has little impact on the detected current.

In a short-circuit fault in the lower-switch $\mathrm{S}_{4}$, the demagnetization current of phase B cannot deplete in a ZVL and the excitation current increases obviously, as shown in Fig. 14(a). However, the voltage can also be regulated in the phase turn-on region and the actual phase $\mathrm{A}$ and $\mathrm{C}$ currents are not affected by the fault in phase B. Fig. 14(b) shows the phase B current detection by employing the PWM injection scheme when $\mathrm{S}_{4}$ is short-circuited. The demagnetization current of phase B is always present in the dc-link current, and the detected phase $A$ and $C$ currents under PWM injection will both contain the demagnetization current of phase B. If the short-circuit fault occurs in the upper-switch $\mathrm{S}_{3}$, the voltage cannot be regulated in the phase turn-on region, and the demagnetization current of phase $B$ is also in a ZVL in the phase turn-off region, which is similar to the short-circuit fault in the lower-switch, as shown in Fig. 14(c). Clearly, the detected phase A and C currents are not affected by the fault, and can, thus, be used to distinguish the short-circuit fault from the upper-switch or the lower-switch. Fig. 14(d) shows the phase B current detection under PWM injection when $\mathrm{S}_{3}$ is short-circuited.

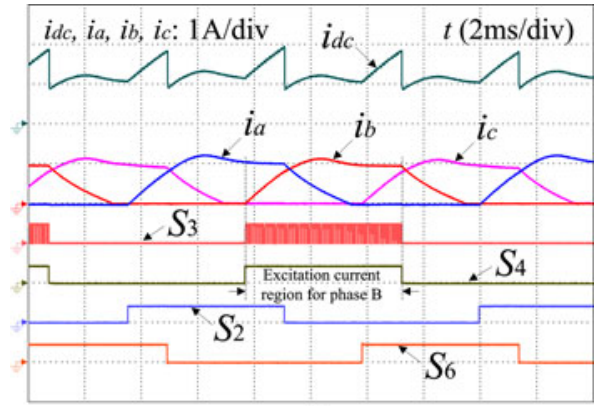

(a)

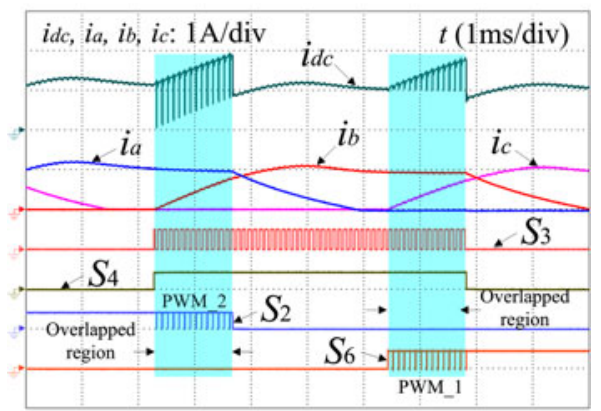

(b)

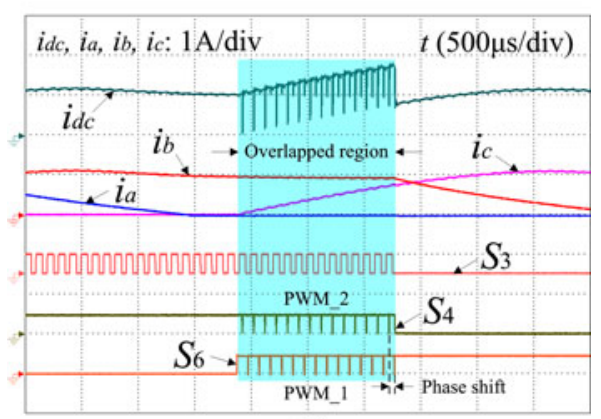

(c)

Fig. 13. Phase current detection in healthy condition under PWM injection (a) Healthy condition without PWM injection. (b) Phase B current detection. (c) Current separation for phases B and C from dc-link current.

The motor drive will work in the absence of one phase leg, no matter the open-circuit fault occurs in the upper-switch or in the lower-switch. In Fig. 15(a), the phase B current is disappeared when the upper-switch $\mathrm{S}_{3}$ is open-circuited. Hence, there is no detected current in phase B under PWM injection, as shown in Fig. 15(b). The dc-link current is only phase A current in the overlapped region of phases $\mathrm{A}$ and $\mathrm{B}$, and only phase $\mathrm{C}$ current in the overlapped region of phases B and C.

Fig. 16 shows the dynamic speed response and the transient progression of the closed-loop system in faulty conditions. The motor can remain operational due to the phase isolation and fault tolerance characteristics of the SRM drive. Phase A and C currents are not affected by the open- and short-circuit faults in the phase B leg. As illustrated in the figure, the motor speed is stabilized within two current fundamental periods and follows the given values well regardless of the open- and short-circuit faults. This is due to the PI algorithm, which ensures a fast and accurate detection for the steady-state currents. 


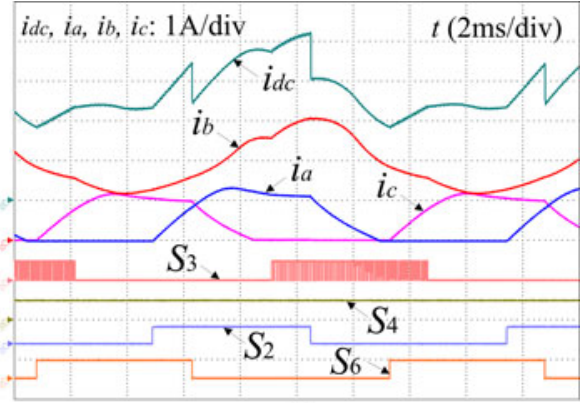

(a)

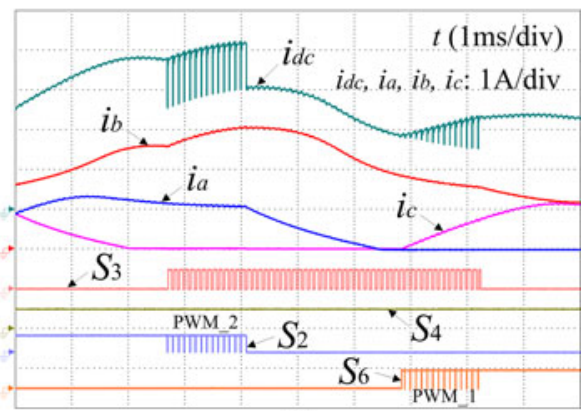

(b)

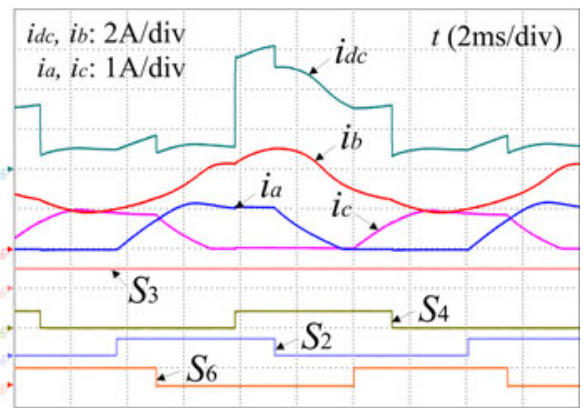

(c)

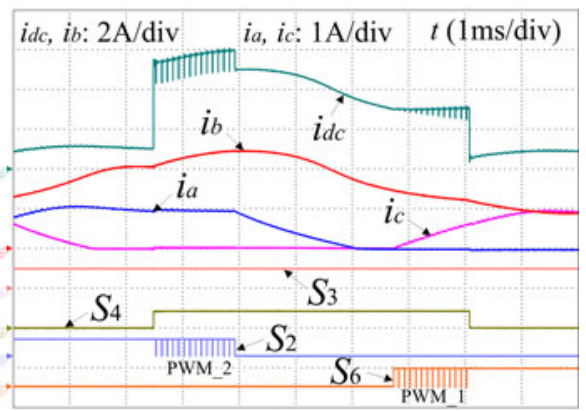

(d)

Fig. 14. Phase current detection for the short-circuit fault. (a) Short-circuit fault in the lower-switch. (b) Phase B current detection when the lower-switch is short-circuited. (c) Short-circuit fault in the upper-switch. (d) Phase B current detection when the upper-switch is short-circuited.

\section{B. Extraction of Fault Coefficient}

The WPD algorithm is used to find the fault coefficient. The orthogonal mother wavelet " $d b 3$ " are selected to implement the WPD algorithm in the sampled currents. In order to make an accurate division of the frequency band to ensure the analysis precision, the five-level decomposition is selected. Considering

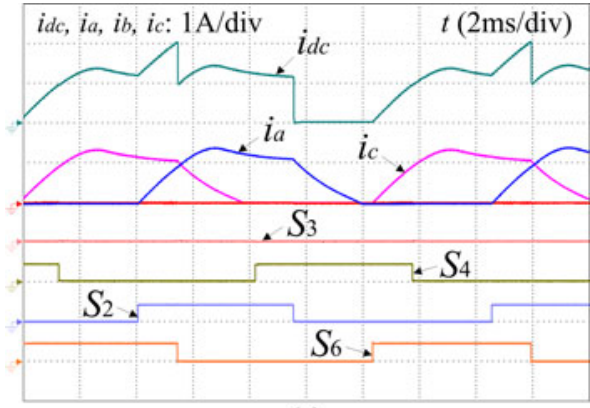

(a)

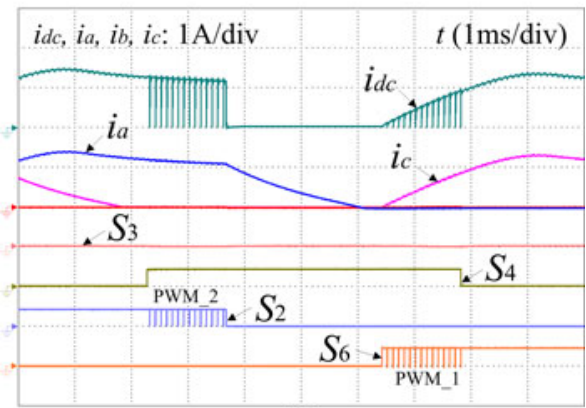

(b)

Fig. 15. Phase current detection for the open-circuit fault. (a) Open-circuit fault in the upper-switch. (b) Phase B current detection when the upper-switch is open-circuited.

that the nodes after five-level decomposition are too many and the nodes energy is more concentrated on the low-frequency band, the first eight nodes are used to extract the fault features to reduce the computational complexity. Table II shows the frequency bandwidth and corresponding nodes for the first eight nodes, where $f$ is the Nyquist frequency, i.e., half of the current sampling frequency.

Fig. 17 presents the discrete degree of the wavelet packet node energy calculated from the detected excitation currents before and after the short-circuit faults at different speeds. In Fig. 17(a), curve $a$ is the discrete degree of phase B current under healthy conditions; and curves $b, c$, and $d$ are the discrete degrees of phase $\mathrm{B}, \mathrm{A}$, and $\mathrm{C}$ currents, respectively, when the upper-switch $\mathrm{S}_{3}$ is short-circuited. In normal operations, the discrete degree decreases when the motor speed is up to 800 $\mathrm{r} / \mathrm{min}$ and is stabilized around 18 above $800 \mathrm{r} / \mathrm{min}$. However, the value is obviously increased by $32 \%$ at $200 \mathrm{r} / \mathrm{min}$ and $66.7 \%$ at $1500 \mathrm{r} / \mathrm{min}$, when a short-circuit fault occurs in the upperswitch, while the discrete degrees of phase A and C currents both remain in the normal state, which can be used for the fault diagnosis.

In Fig. 17(b), curve $a$ is the discrete degree of phase B current under healthy conditions; and curves $e, f$, and $g$ are the discrete degrees of phase $\mathrm{B}, \mathrm{A}$, and $\mathrm{C}$ currents, respectively, when the lower-switch $\mathrm{S}_{4}$ is short-circuited. In this faulty condition, the discrete degree of phase $\mathrm{B}$ current also increases and the value is similar to the upper-switch short-circuited condition. Nonetheless, the discrete degrees of the detected phase A and C currents both increase, due to the demagnetization current of phase $\mathrm{B}$ in the lower ZVL, which is used to tell whether the short-circuit fault occurs in the upper-switch or the lower-switch. 


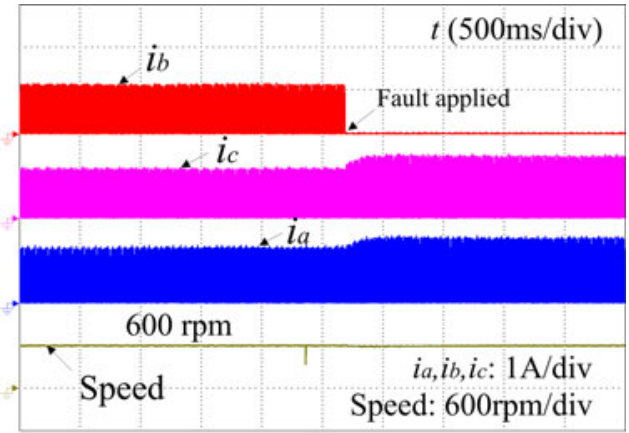

(a)

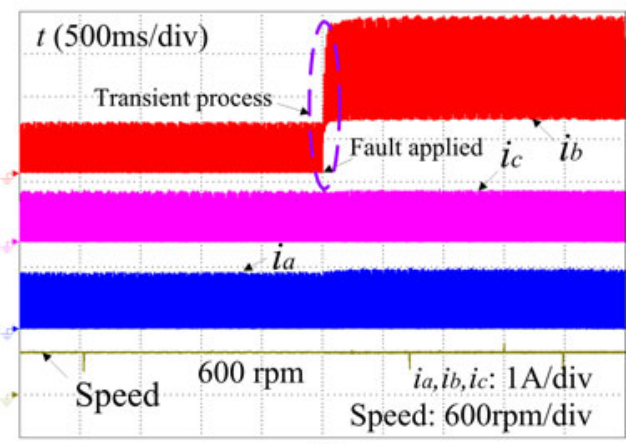

(b)

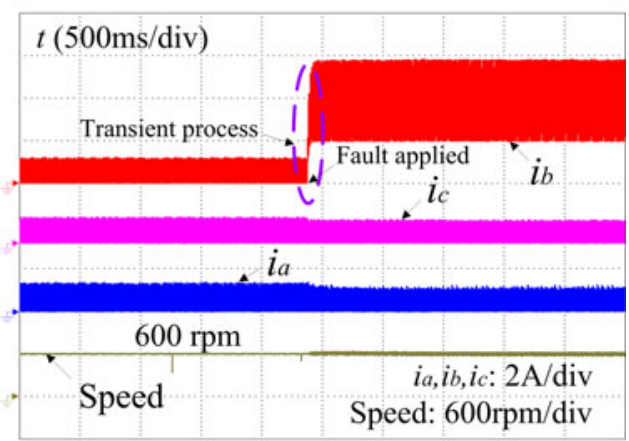

(c)

Fig. 16. Transient response of the closed-loop system in faulty conditions. (a) Open-circuit fault in the lower-switch. (b) Short-circuit fault in the lowerswitch. (c) Short-circuit fault in the upper-switch.

TABLE II

FREQUENCY BANDWIDTH AND CORRESPONDING NODES

\begin{tabular}{lccc}
\hline \hline Bandwidth & Node & Bandwidth & Node \\
\hline$(0, f / 32)$ & $(5,0)$ & $(f / 8,5 f / 32)$ & $(5,6)$ \\
$(f / 32, f / 16)$ & $(5,1)$ & $(5 f / 32,3 f / 16)$ & $(5,7)$ \\
$(f / 16,3 f / 32)$ & $(5,3)$ & $(3 f / 16,7 f / 32)$ & $(5,5)$ \\
$(3 f / 32, f / 8)$ & $(5,2)$ & $(7 f / 32, f / 4)$ & $(5,4)$ \\
\hline \hline
\end{tabular}

Phase B current is disappeared when the upper-switch $S_{3}$ is open-circuited; hence, the discrete degree of the nodes energy will sharply drop to zero when the fault happens. Thus, the open-circuit fault can be just diagnosed by checking if the fault coefficient changes to zero. However, it should be noted that the asymmetrical half-bridge converter employs two power switches in each phase with phase isolation and fault tolerance



(a)

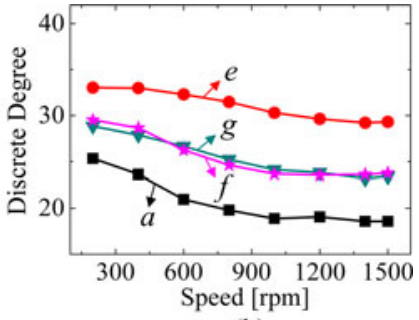

(b)
Fig. 17. Discrete degree before and after the faults. (a) Upper-switch shortcircuit. (b) Lower-switch short-circuit.

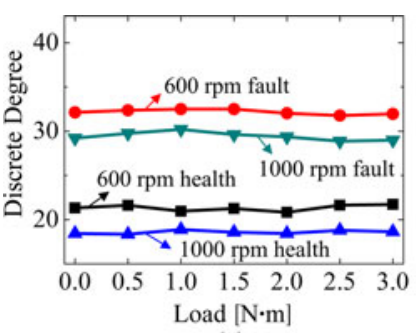

(a)

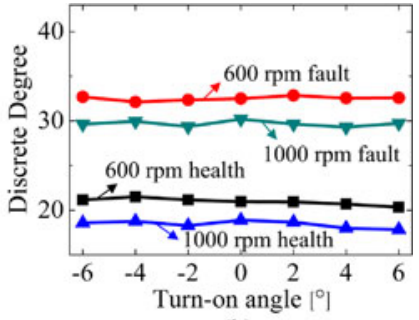

(b)
Fig. 18. Impact of the load and turn-on angle on the discrete degree of shortcircuit fault in the upper-switch. (a) Discrete degree under different loads. (b) Discrete degree under different turn-on angles.

features. The two switches and phase winding are connected in series. The current can be supplied to the phase winding only when the two switches are both turned ON. No matter an open-circuit fault occurs in the upper-switch or the lowerswitch, the affected phase will be in the phase absent state, presenting the same faulty condition. Therefore, in the case of open-circuit faults, due to the specific features of the power converter topology, there could not be able to locate the faulty IGBT in upper-switch or lower-switch if the fault occurs.

Additionally, in order to study the robustness of the fault coefficient to the variations of system parameters, the investigations for the discrete degree of the wavelet packet node energy, calculated from the detected excitation currents before and after the short-circuit fault in the upper-switch, under different loads and turn-on angles are presented in Fig. 18. The fault coefficient has good robustness both to the load and turn-on angle variations. Therefore, the proposed scheme is particularly suitable for low cost, variable load operation, and variable angle modulation systems. By determining the changes in the proposed discrete degree of the wavelet packet node energy calculated from the detected excitation current, open- and short-circuit faults of power switches can be accurately identified.

\section{CONCLUSION}

This paper has presented a new fault diagnosis scheme for SRM drives using a WPD algorithm and a single dc-link current sensor. This reduces the number of current sensors to one for effective fault diagnosis. Open- and short-circuit faults of power switches in a conventional asymmetrical half-bridge converter can be accurately identified. Two PWM signals with the same frequency and duty-cycle under phase-shift modulation 
are simultaneously injected into the lower-switches to obtain the phase current characteristics from the dc-link current, and a discrete degree of the wavelet packet node energy is presented to be the fault coefficient for fault diagnosis. Compared with existing methods, the proposed scheme requires only one current sensor in the dc link without any additional hardware investment and much change to the circuitry. The new current sensor placement strategy offers a low-cost solution to typical power switch faults. The proposed scheme is found to be accurate and easy to implement for fault diagnosis purposes. The responses of the extracted fault coefficient to variations of the system parameters including speed, load and turn-on angle modulations are proved to be excellent from testing a 750-W three-phase SRM.

\section{REFERENCES}

[1] K. Kiyota, T. Kakishima, and A. Chiba, "Comparison of test result and design stage prediction of switched reluctance motor competitive with 60-kW rare-earth PM motor,' IEEE Trans. Ind. Electron., vol. 61, no. 10, pp. 5712-5721, Oct. 2014.

[2] R. Vandana and B. G. Fernandes, "Design methodology for highperformance segmented rotor switched reluctance motors," IEEE Trans. Energy Convers., vol. 30, no. 1, pp. 11-21, Mar. 2015.

[3] J. Ye, B. Bilgin, and A. Emadi, "An extended-speed low-ripple torque control of switched reluctance motor drives," IEEE Trans. Power Electron., vol. 30, no. 3, pp. 1457-1470, Mar. 2015.

[4] A. Chiba, K. Kiyota, N. Hoshi, M. Takemoto, and S. Ogasawara, "Development of a rare-earth-free SR motor with high torque density for hybrid vehicles," IEEE Trans. Energy Convers., vol. 30, no. 1, pp. 175-182, Mar. 2015.

[5] D. H. Lee and J. W. Ahn, "A novel four-level converter and instantaneous switching angle detector for high speed SRM drive," IEEE Trans. Power Electron., vol. 22, no. 5, pp. 2034-2041, Sep. 2007.

[6] L. Szabo and M. Ruba, "Segmental stator switched reluctance machine for safety-critical applications," IEEE Trans. Ind. Appl., vol. 48, no. 6, pp. 2223-2229, Nov./Dec. 2012.

[7] M. Takeno, A. Chiba, N. Hoshi, S. Ogasawara, M. Takemoto, and M. A. Rahman, "Test results and torque improvement of the $50-\mathrm{kW}$ switched reluctance motor designed for hybrid electric vehicles," IEEE Trans. Ind. Appl., vol. 48, no. 4, pp. 1327-1334, Jul./Aug. 2012.

[8] K. Kiyota, T. Kakishima, H. Sugimoto, and A. Chiba, "Comparison of the test result and 3D-FEM analysis at the knee point of a $60 \mathrm{~kW}$ SRM for a HEV," IEEE Trans. Magn., vol. 49, no. 5, pp. 2291-2294, May 2013.

[9] Y. Hu, X. Song, W. Cao, and B. Ji, "New SR drive with integrated charging capacity for plug-in hybrid electric vehicles (PHEVs)," IEEE Trans. Ind. Electron., vol. 61, no. 10, pp. 5722-5731, Oct. 2014.

[10] F. L. M. dos Santos, J. Anthonis, F. Naclerio, J. J. C. Gyselinck, H. V. D. Auweraer, and L. C. S. Goes, "Multiphysics NVH modeling: Simulation of a switched reluctance motor for an electric vehicle," IEEE Trans. Ind. Electron., vol. 61, no. 1, pp. 469-476, Jan. 2014.

[11] L. A. Belfore II and A. Arkadan, "A methodology for characterizing fault tolerant switched reluctance motors using neurogenetically derived models," IEEE Trans. Energy Convers., vol. 17, no. 3, pp. 380-384, Sep. 2002.

[12] S. Mir, M. S. Islam, T. Sebastian, and I. Husain, "Fault-tolerant switched reluctance motor drive using adaptive fuzzy logic controller," IEEE Trans. Power Electron., vol. 19, no. 2, pp. 289-295, Mar. 2004.

[13] M. D. Hennen, M. Niessen, C. Heyers, H. J. Brauer, and R. W. De Doncker, "Development and control of an integrated and distributed inverter for a fault tolerant five-phase switched reluctance traction drive," IEEE Trans. Power Electron., vol. 27, no. 2, pp. 547-554, Feb. 2012.

[14] I. Jlassi, J. O. Estima, S. K. El Khil, N. M. Bellaaj, and A. J. M. Cardoso, "Multiple open-circuit faults diagnosis in back-to-back converters of PMSG drives for wind turbine systems," IEEE Trans. Power Electron., vol. 30, no. 5, pp. 2689-2702, May 2015.

[15] L. M. A. Caseiro and A. M. S. Mendes, "Real-time IGBT open-circuit fault diagnosis in three-level neutral-point-clamped voltage-source rectifiers based on instant voltage error," IEEE Trans. Ind. Electron., vol. 62, no. 3, pp. 1669-1678, Mar. 2015.
[16] X. Pei, S. Nie, and Y. Kang, "Switch short-circuit fault diagnosis and remedial strategy for full-bridge DC-DC converters," IEEE Trans. Power Electron., vol. 30, no. 2, pp. 996-1004, Feb. 2015.

[17] M. A. Awadallah and M. M. Morcos, "Automatic diagnosis and location of open-switch fault in brushless DC motor drives using wavelets and neuro-fuzzy systems," IEEE Trans. Energy Convers., vol. 21, no. 1, pp. 104-111, Mar. 2006.

[18] J. Fang, W. Li, H. Li, and X. Xu, "Online inverter fault diagnosis of buck-converter BLDC motor combinations," IEEE Trans. Power Electron., vol. 30, no. 5, pp. 2674-2688, May 2015.

[19] S. M. Jung, J. S. Park, H. W. Kim, K. Y. Cho, and M. J. Youn, "An MRASbased diagnosis of open-circuit fault in PWM voltage-source inverters for PM synchronous motor drive systems," IEEE Trans. Power Electron., vol. 28, no. 5, pp. 2514-2526, May 2013.

[20] Q. T. An, L. Sun, and L. Z. Sun, "Current residual vector-based openswitch fault diagnosis of inverters in PMSM drive systems," IEEE Trans. Power Electron., vol. 30, no. 5, pp. 2814-2827, May 2015.

[21] J. Zhang, J. Zhao, D. Zhou, and C. Huang, "High-performance fault diagnosis in PWM voltage-source inverters for vector-controlled induction motor drives," IEEE Trans. Power Electron., vol. 29, no. 11, pp. 6087-6099, Nov. 2014

[22] S. Gopalakrishnan, A. M. Omekanda, and B. Lequesne, "Classification and remediation of electrical faults in the switched reluctance drive," IEEE Trans. Ind. Appl., vol. 42, no. 2, pp. 479-486, Mar./Apr. 2006.

[23] L. A. Belfore II and A. R. A. Arkadan, "Modeling faulted switched reluctance motors using evolutionary neural networks," IEEE Trans. Ind. Electron., vol. 44, no. 2, pp. 226-233, Apr. 1997.

[24] L. A. Belfore II and A. Arkadan, "A methodology for characterizing fault tolerant switched reluctance motors using neurogenetically derived models," IEEE Trans. Energy Convers., vol. 17, no. 3, pp. 380-384, Sep. 2002.

[25] H. Chen and S. Lu, "Fault diagnosis digital method for power transistors in power converters of switched reluctance motors," IEEE Trans. Ind. Electron., vol. 60, no. 2, pp. 749-763, Feb. 2013.

[26] N. S. Gameiro and A. J. M. Cardoso, "A new method for power converter fault diagnosis in SRM drives," IEEE Trans. Ind. Appl., vol. 48, no. 2, pp. 653-662, Mar./Apr. 2012.

[27] J. F. Marques, J. O. Estima, N. S. Gameiro, and A. J. M. Cardoso, "A new diagnostic technique for real-time diagnosis of power converter faults in switched reluctance motor drives," IEEE Trans. Ind. Appl., vol. 50, no. 3, pp. 1854-1860, May/Jun. 2014.

[28] N. S. Gameiro and A. J. M. Cardoso, "Supply current polar chart analysis of SRM drives under normal and faulty operating conditions," in Proc. Int. Conf. Power Eng., Energy Elect. Drives, Lisbon, Portugal, Mar. 18-20, 2009, pp. 455-460.

[29] C. M. Stephens, "Fault detection and management system for fault-tolerant switched reluctance motor drives," IEEE Trans. Ind. Appl., vol. 27, no. 6, pp. 1098-1102, Nov./Dec. 1991.

[30] K. J. Lee, N. J. Park, K. H. Kim, and D. S. Hyun, "Simple fault detection and tolerant scheme in VSI-fed switched reluctance motor," in Proc. IEEE Power Electron. Spec. Conf., Seoul, Korea, Jun. 18-22, 2006, pp. 1-6.

[31] P. Bogusz, M. Korkosz, and J. Prokop, "Current harmonics analysis as a method of electrical faults diagnostic in switched reluctance motors," in Proc. Int. Symp. Diagnostics Elect. Mach., Power Electron. Drives, Cracow, Poland, Sep. 6-8, 2007, pp. 426-431.

[32] N. S. Gameiro and A. J. M. Cardoso, "Fault tolerant control strategy of SRM drives," in Proc. IEEE Int. Symp. Power Electron., Elect. Drives, Autom. Motion, Ischia, Italy, Jun. 11-13, 2008, pp. 301-306.

[33] H. Lu, X. Cheng, W. Qu, S. Sheng, Y. Li, and Z. Wang, "A three-phase current reconstruction technique using single DC current sensor based on TSPWM," IEEE Trans. Power Electron., vol. 29, no. 3, pp. 1542-1550, Mar. 2014.

[34] Y. Gu, F. Ni, D. Yang, and H. Liu, "Switching-state phase shift method for three-phase-current reconstruction with a single DC-link current sensor," IEEE Trans. Ind. Electron., vol. 58, no. 11, pp. 5186-5194, Nov. 2011.

[35] H. Kim and T. M. Jahns, "Current control for AC motor drives using a single DC-link current sensor and measurement voltage vectors," IEEE Trans. Ind. Appl., vol. 42, no. 6, pp. 1539-1547, Nov./Dec. 2006.

[36] C. Gan, J. Wu, S. Yang, and Y. Hu, "Phase current reconstruction of switched reluctance motors from dc-link current under double highfrequency pulses injection," IEEE Trans. Ind. Electron., vol. 62, no. 5, pp. 3265-3276, May 2015. 
[37] H. Ye and A. Emadi, "A six-phase current reconstruction scheme for dual traction inverters in hybrid electric vehicles with a single DC-link current sensor," IEEE Trans. Veh. Technol., vol. 63, no. 7, pp. 3085-3093, Sep. 2014.

[38] H. Kim, M. Falahi, T. M. Jahns, and M. W. Degner, "Inductor current measurement and regulation using a single DC link current sensor for interleaved DC-DC converters," IEEE Trans. Power Electron., vol. 26, no. 5, pp. 1503-1510, May 2011.

[39] Z. Ye, B. Wu, and A. Sadeghian, "Current signature analysis of induction motor mechanical faults by wavelet packet decomposition," IEEE Trans. Ind. Electron., vol. 50, no. 6, pp. 1217-1228, Dec. 2003.

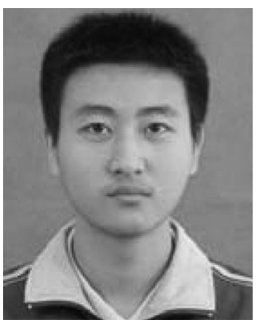

Chun Gan (S'14) received the B.S. and M.S. degrees in power electronics and drives from the China University of Mining and Technology, Jiangsu, China, in 2009 and 2012, respectively. He is currently working toward Ph.D. degree at the College of Electrical Engineering, Zhejiang University, Hangzhou, China.

His research interests include electrical motor drives, motor design, control with emphasis on switched reluctance motor sensorless technique, and optimization of the torque ripple and efficiency of the motor system.

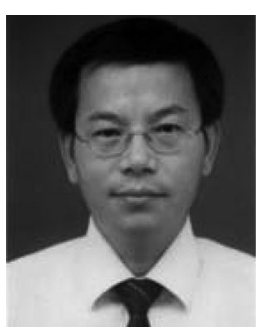

Jianhua Wu received the B.S. degree from the Nanjing University of Aeronautics and Astronautics, Nanjing, China, and the M.S. and Ph.D. degrees from the Huazhong University of Science and Technology, Huazhong, China, in 1983, 1991, and 1994, respectively, all in electrical engineering.

From 1983 to 1989, he was with Guiyang Electric Company, Guizhou, China, as a Design Engineer. Since 2005, He has been a Professor at the College of Electrical Engineering, Zhejiang University, Zhejiang, China. He developed the motor design software Visual EMCAD, which is widely used in China. His research interests are electric machine design and drives, including switched reluctance motors, and permanent magnet machines for electric vehicle applications.

Dr. Wu is a Member of the Electrical Steel of Chinese Society for Metals, the Small-Power Machine Committee of China Electrotechnical Society, and the Standardization Administration of China.

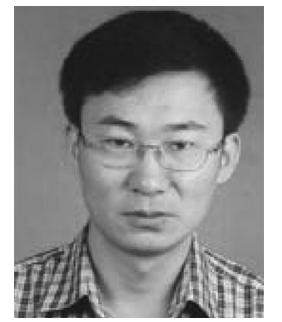

Shiyou Yang received the M.S. and Ph.D. degrees from the Shenyang University of Technology, Liaoning, China, in 1990 and 1995, respectively, both in electrical engineering.

He is currently a Professor at the College of Electrical Engineering, Zhejiang University, Hangzhou, China. His research interests include computational electromagnetics.

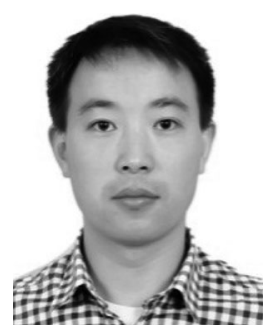

Yihua Hu (M'13-SM'15) received the B.S. degree in electrical motor drives and the Ph.D. degree in power electronics and drives from the China University of Mining and Technology, Jiangsu, China, in 2003 and 2011, respectively.

Between 2011 and 2013, he was with the College of Electrical Engineering, Zhejiang University, Zhejiang, China, as a Postdoctoral Fellow. Between November 2012 and February 2013, he was an Academic Visiting Scholar with the School of Electrical and Electronic Engineering, Newcastle University, Newcastle, U.K. He is currently a Research Associate with the Department of Electronic and Electrical Engineering, University of Strathclyde, Glasgow, U.K. His research interests include photovoltaic generation system, power electronics converters and control, and electrical motor drives.

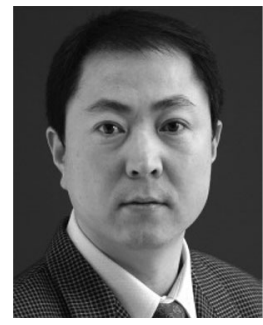

Wenping Cao (M'05-SM'11) received the B.Eng. degree in electrical engineering from Beijing Jiaotong University, Beijing, China, in 1991, and the Ph.D. degree in electrical machines and drives from the University of Nottingham, Nottingham, U.K., in 2004

$\mathrm{He}$ is currently a Marie Curie Fellow with the Department of Electrical Engineering and Computer Science, Massachusetts Institute of Technology, Cambridge, MA, USA, and a Senior Lecturer with Queen's University Belfast, Belfast, U.K. His research interests include thermal performance and fault analysis of electric machines, drives, and power electronics.

Dr. Cao received the Best Paper Award at the Linear Drives for Industry Applications 2013 Conference; the Innovator of the Year Award from Newcastle University, Newcastle upon Tyne, U.K., in 2013; and the Dragon's Den Competition Award from Queen's University Belfast, in 2014. He serves as an Associate Editor for the IEEE TRANSACTIONS ON INDUSTRY APPLICATIONS, the IEEE INDUSTRY APPLICATIONS MAGAZINE, IET Power Electronics, and nine other international journals. He is also a Member of the Institution of Engineering and Technology, and a Fellow of the Higher Education Academy. 